\title{
Dietary fat and obesity: lack of an important role*
}

\author{
Walter C. Willett
}

Departments of Epidemiology and Nutrition, Harvard School of Public Health, Boston, Massachusetts, USA

\section{Abstract}

The percentage of dietary energy from fat has been suggested to be an important determinant of body fat, and this presumed effect has been used to promote low-fat diets. In short-term randomized trials, a small reduction in body weight is typically seen in individuals randomized to diets with a lower percentage of calories from fat. However, in trials lasting for 1 year or longer, fat consumption within the range of $18-40 \%$ of energy had consistently had little if any effect on body fatness. The weighted mean difference was $-0.25 \mathrm{~kg}$ overall and $+1.8 \mathrm{~kg}$ for trials with a control group that received a comparable intensity intervention (i.e. less weight loss on the low-fat diets). Moreover, in the USA and other affluent countries, a substantial decline in the percentage of energy from fat during the past two decades has corresponded with a massive increase in obesity. Diets high in fat do not account for the high prevalence of excess body fat in Western countries; reductions in the percentage of energy from fat will have no important benefits and could further exacerbate this problem.

Keywords: adiposity; diet; fat; obesity; overweight

\section{Introduction}

In the USA and many other affluent countries, excess body fat accounts for approximately $30-40 \%$ of coronary heart disease cases $(2,3)$, many cancers of the colon, breast, kidney and endometrium (4), most cases of adult-onset diabetes (5) and a substantial proportion of disabling osteoarthritis (6). Overweight and obesity is thus the largest nutritionally related problem in the developed world. Rapid increases in obesity are occurring in many developed countries (7), where the adverse impacts on health will inevitably follow. Genetic factors influence which individuals within a population will develop adiposity, but cannot account for the high rates of excessive body fat in most Western populations. This is supported by dramatic increases in overweight among migrants from countries with minimal adiposity who come to the USA, such as the three-fold higher prevalence of obesity in Japanese men living in San Francisco compared with those in Japan (8). In addition, major increases in adiposity are occurring within many populations (7, 9-11), which cannot be explained by genetic factors. Dietary fat has been among the lifestyle factors most often claimed to be responsible for

\footnotetext{
${ }^{*}$ Reproduced in part with permission from Obesity Reviews (1).
}

these high rates of adiposity. Because fat intake per se is unrelated to risk of cardiovascular disease (12) and also does not appear to be importantly related to cancer incidence, a reduction in obesity has been a primary justification for recommendations to reduce dietary fat (13). Some nutritionists believe that a reduction in the percentage of energy from fat will lead to a "spontaneous" reduction in body weight and an important reduction in the prevalence of obesity $(14,15)$.

Several mechanisms have been proposed to explain why high fat intake might lead to greater body fat $(16,17)$. Dietary fat is the most energydense macronutrient in the diet, providing approximately $38 \mathrm{~kJ} \mathrm{~g}^{-1}$ as opposed to $17 \mathrm{~kJ} \mathrm{~g}^{-1}$ for carbohydrate or protein; this could lead to overconsumption of energy if food volume is regulated. Fats are often said to lend greater flavor and palatability to foods, which could thus increase their consumption. In addition, when studied under careful metabolic conditions for short periods, carbohydrate produces a greater thermogenic effect than fat, suggesting that dietary fat may be utilized more efficiently and accumulate as body fat (18). Finally, Flatt (19) suggested that carbohydrate intake, but not fat intake, is regulated; thus, individuals on a high-fat diet would tend to con- 
sume more total energy to gain the required amount of carbohydrate than would someone on a low-fat diet. Although these mechanisms may seem compelling at face value, we rarely eat foods that are pure fat or carbohydrate, and the energy for weight of foods is more determined by the water and fiber content. For example, a salad with oil dressing can provide a high percentage of energy from fat but have a low energy density. In addition, when carefully controlled metabolic studies are extended even to just 4 days, there are no differences in stored energy when fat or carbohydrate is overfed (20). Further, our understanding of the mechanisms that regulate weight over months and years remain rudimentary, so that short-term studies may be completely misleading. Nevertheless, dietary fat composition must be considered as a possible important determinant of body fat. If a reduction in the percentage of energy from fat in the diet has a substantial effect on body fatness, this would be a major reason to consider low-fat diets.

\section{Empirical evidence}

\section{Between-population (ecological) studies}

The prevalence of overweight in affluent countries with high fat intakes tends to be higher than in poorer regions of the world with low-fat diets, which has often been used to support a causal relation between dietary fat and body fat. However, such observations are strongly confounded by the availability of food and level of physical activity, so that such comparisons can be seriously misleading. Comparisons within regions of the world with similar degrees of economic development can be more informative. Among European countries, no association was observed for men between the national percentage of energy from fat and median body mass index (BMI), even though fat intake varied from approximately 25 to $47 \%$ of energy (21). For women a clear inverse relation was observed (21). Among 65 counties in China, no correlation was found between dietary fat intake, which ranged from approximately 8 to $25 \%$ of energy, and body weight (22). Geographical correlations such as these have many limitations, including differences in the quality of dietary data and confounding by unmeasured variables such as activity levels, smoking and cultural attitudes towards body fat. Nevertheless, the lack of any clear, positive association between dietary fat intake and obesity among areas with roughly similar degrees of affluence provides evidence against an important causal relationship.

Time trends in dietary fat and adiposity within countries in transition from poverty or agrarian lifestyles to greater affluence are likely to be confounded by changes in food availability and level of physical activity because higher fat intake typically accompanies newly gained affluence. Thus, the observation by Bray and Popkins (10) that an increase in $10 \%$ of energy in China corresponds to an increase in BMI of $0.03 \mathrm{~kg} \mathrm{~m}^{-2}$ is impossible to interpret except that it is extremely small, even if real (23). In the USA and several northern European countries, fat intake and affluence have been disassociated owing to conscious efforts by the food industry, professional organizations and governmental bodies to reduce fat intake (7). Thus, it is notable that as fat intake has declined as a percentage of energy over the past 25 years the prevalence of obesity has dramatically increased in the USA $(11,12,24)$. This is a strong refutation of the notion that adiposity will "spontaneously" decline as the percentage of energy from fat is reduced.

\section{Within-population correlations}

Many cross-sectional studies have been conducted to examine the correlation between dietary fat and body fatness within populations. Results have been inconsistent; positive associations have been seen in some studies (25-35), but not in others $(28,29,33$, $35,36)$. Unfortunately, most cross-sectional studies within populations are also prone to confounding that is almost uniquely problematic. In most populations studied, both the avoidance of dietary fat and the desirability of being lean have become strongly linked with general health consciousness. Confounding is particularly intractable in this context because health-conscious people are aware of and can influence the primary determinants of body weight, specifically dietary restraint and physical activity. Both of these are measured imperfectly in free-living populations and thus difficult to control for statistically. Therefore, it should not be surprising that the fat composition of the diet is often positively associated with body fat in cross-sectional studies. Body fatness is readily apparent to the individual, who may alter dietary intake on account of weight or weight gain. Prospective studies are generally considered a substantially stronger epidemiological design than are 
cross-sectional studies. However, they are similarly susceptible to serious confounding when individuals are aware of the dependent variable, here body weight, and also have conscious control over its primary determinants, physical activity and total energy intake, as well as the percentage of energy from fat. Relatively few prospective studies of dietary fat and weight change have been published $(31,34,35,37,38)$, and the findings are inconsistent. The large prospective study by Colditz et al. (31) provided evidence of confounding by health consciousness and an intent to lose weight. In this cohort of 31940 women followed for 4 years, weight gain was weakly positively associated with animal fat intake (generally viewed as unhealthy) but was weakly negatively associated with vegetable fat (generally viewed as healthy), even though there is little reason to believe that these would be metabolically distinct in relation to weight gain. Total fat intake was not associated with long-term weight gain.

Because of the serious potential for confounding that is extremely difficult to control, both crosssectional and prospective studies are likely to be particularly unhelpful in determining the causal relationship between the fat composition of diets and body fat.

\section{Randomized trials}

Randomized trials are clearly the most desirable way to determine the effects of dietary fat on body fat because of the potential for confounding in studies among populations and among individuals within populations. Surprisingly few randomized trials have been designed to address this issue.

In short-term randomized trials, those lasting from a few weeks up to 6 months, modest weight losses ( $<1 \mathrm{~kg}$ to $4 \mathrm{~kg}$ ) are typically seen when $10_{-}$ $15 \%$ of energy from fat is replaced by carbohydrate $(10,14,25,39-44)$. Although the effects of fat reduction on body weight in short-term studies have been modest, these could potentially be important if they were cumulative over periods of years. For example, in a meta-analysis that included 28 mainly short-term trials, Bray and Popkins (10) estimated that a reduction of $10 \%$ of total energy intake from fat would reduce body weight by $16 \mathrm{~g} \mathrm{~d}^{-1}$. This would predict a weight difference of $8.8 \mathrm{~kg}$ by 18 months and $23.4 \mathrm{~kg}$ by 4 years. Thus, long-term studies are critical to assess this prediction.
Longer term randomized trials of fat reduction and body weight are few and most data are secondary observations from studies in which body weight was not the primary outcome. Most were pilot studies of fat reduction for the prevention of cancer or cardiovascular disease (Table 1) (38, 45-50). The only double-blind, longer term study of fat reduction appears to be the National Diet Heart Study (45) conducted among 900 individuals, in which foods with variable fat content were provided to participants. The difference in fat intake between groups was $30 \%$ compared with $35 \%$ of energy, and after approximately 1 year the difference in weight was only $0.8 \mathrm{~kg}$ (51). This difference in fat intake, while not large, is similar to the difference between current US diets and the US dietary goals for fat intake, and therefore provides a clear indication that achieving this goal would have no important effect on adiposity.

Four longer term trials of fat reduction were pilot studies for interventions targeting cancer. In the Women's Health Trial (38) fat intake was to be reduced from approximately 38 to $20 \%$ of energy. Reported compliance was nearly perfect by 6 months and decreased only modestly by 24 months. Women in the low-fat group lost $3.2 \mathrm{~kg}$ of body weight by 6 months; however, some of this was regained so that by 24 months they had only lost 1.9 $\mathrm{kg}$ and the difference between the intervention and control group was $1.8 \mathrm{~kg}$. This study strongly suggests that weight losses on low-fat diets are not cumulative over time and are in part transient. This pilot study has been implemented in a full-scale breast cancer prevention trial, the Women's Health Initiative, in which over 30000 women have been randomized to a low-fat or regular diet for 10 years. This study, which is past the midway point, is clearly the largest trial of low-fat diet and body weight, but no official results have been published. In a trial of fat reduction in the prevention of skin cancer (48), the reduction in body fat on a low-fat diet relative to the control diet was only about $1 \mathrm{~kg}$. In another feasibility trial for breast cancer prevention, 194 women were randomized to a $15 \%$ of energy low-fat diet or a non-intervention group (50). Drop-outs were significantly greater on the low-fat diet, so that by 12 months $69 \%$ remained on the study compared with $81 \%$ in the control group $(p=0.009)$. At 12 months, weight loss was $1.5 \mathrm{~kg}$ in the low-fat group and $2.4 \mathrm{~kg}$ in the control group. 
Table I. Long-term trials of fat reduction and body weight

\begin{tabular}{|c|c|c|c|c|c|c|c|}
\hline Study & $\begin{array}{l}\text { Length of } \\
\text { trial } \\
\text { (months) }\end{array}$ & $n$ & $\begin{array}{l}\text { Fat in } \\
\text { diet } \\
(\%)\end{array}$ & $\begin{array}{l}\text { Greatest } \\
\text { weight loss } \\
\text { (kg) }\end{array}$ & $\begin{array}{l}\text { Change in weight } \\
\text { at end trial } \\
(\mathrm{kg})\end{array}$ & $\begin{array}{l}\text { Weight loss } \\
\text { difference } \\
(\mathbf{k g})\end{array}$ & Comments \\
\hline $\begin{array}{l}\text { National Diet-Heart Study } \\
\text { (5I) }\end{array}$ & $12-20$ & $\begin{array}{l}\text { Int } 450 \\
\text { Cont } 450\end{array}$ & $\begin{array}{l}30 \\
35\end{array}$ & $\begin{array}{l}-2.8 \\
-2.3\end{array}$ & $\begin{array}{l}-2.3 \\
-1.5\end{array}$ & -0.8 & The only double-blind study \\
\hline $\begin{array}{l}\mathrm{NCl} \text { feasibility trial for low- } \\
\text { fat diet to reduce breast } \\
\text { cancer risk (38) }\end{array}$ & 24 & $\begin{array}{l}\text { Int } 17 \mid \\
\text { Cont } 105\end{array}$ & $\begin{array}{l}20 \\
38\end{array}$ & $\begin{array}{l}-3.2 \\
-0.4\end{array}$ & $\begin{array}{l}-1.9 \\
-0.1\end{array}$ & $\begin{array}{l}-1.8 \\
-1.0\end{array}$ & $\begin{array}{l}\text { A somewhat large difference at } 6 \\
\text { months became smaller with time }\end{array}$ \\
\hline $\begin{array}{l}\text { Low-fat diet for women } \\
\text { with breast dysplasia (46) }\end{array}$ & 12 & $\begin{array}{l}\text { Int } 100 \\
\text { Cont } 106\end{array}$ & $\begin{array}{l}21 \\
37\end{array}$ & $\begin{array}{c}-2.0 \\
0\end{array}$ & $\begin{array}{c}-1.0 \\
0\end{array}$ & -1.0 & \\
\hline $\begin{array}{l}\text { Effect of low-fat diet on } \\
\text { lipoprotein metabolism (47) }\end{array}$ & 12 & $\begin{array}{l}\text { Int } 34 \\
\text { Cont } 38\end{array}$ & $\begin{array}{l}17 \\
36\end{array}$ & - & $\begin{array}{l}-3.4 \\
-0.8\end{array}$ & -2.6 & $\begin{array}{l}\text { Weight differences reflect changes in } \\
\text { lean as well as fat mass as there were } \\
\text { no differences between groups in } \\
\text { changes in \% body fat or waist-hip } \\
\text { ratio }\end{array}$ \\
\hline $\begin{array}{l}\text { Effect of low-fat diet on } \\
\text { incidence of actinic keratosis } \\
\text { (48) }\end{array}$ & 24 & $\begin{array}{l}\text { Int } 38 \\
\text { Cont } 38\end{array}$ & $\begin{array}{l}21 \\
40\end{array}$ & $\begin{array}{l}-3.0 \\
-1.0\end{array}$ & $\begin{array}{l}-2.0 \\
-1.0\end{array}$ & -1.0 & $\begin{array}{l}\text { No significant differences in weight at } \\
\text { any time during the } 24 \text { months }\end{array}$ \\
\hline $\begin{array}{l}\text { Randomized trial of coun- } \\
\text { seling for fat vs calorie re- } \\
\text { striction in treatment of } \\
\text { obesity (49) }\end{array}$ & 18 & $\begin{array}{l}\text { Int } 39 \\
\text { Cont } 35\end{array}$ & $\begin{array}{l}26 \\
33\end{array}$ & $\begin{array}{l}-4.6 \\
-3.7\end{array}$ & $\begin{array}{l}+0.4 \\
+1.8\end{array}$ & -1.4 & $\begin{array}{l}\text { Fat counseling: }<20 \mathrm{~g} \mathrm{~d}^{-1} \text {, calorie } \\
\text { reduction: } 1000-1200 \mathrm{kcal} \mathrm{d}^{-1} .33 \% \\
\text { of original participants failed to finish } \\
\text { trial. Adherence to both fat and calorie } \\
\text { reduction regimen was poor after } 6 \\
\text { months }\end{array}$ \\
\hline $\begin{array}{l}\text { Treatment of dyslipidemia } \\
\text { (55) }\end{array}$ & 12 & $\begin{array}{l}\text { Int } 78 \\
\text { Cont } 59\end{array}$ & $\begin{array}{l}27 \\
22\end{array}$ & - & $\begin{array}{l}-2.9 \\
-2.9\end{array}$ & 0 & $\begin{array}{l}\text { Additional subjects on intermediate } \\
\text { levels of fat intake also experienced no } \\
\text { difference in weight } \\
\text { loss. The lowest fat group experienced } \\
\text { a } 39 \% \text { increase in plasma fasting } \\
\text { triglyceride level, indicating compliance } \\
\text { with low fat intake }\end{array}$ \\
\hline $\begin{array}{l}\text { Pilot study of low-fat diet } \\
\text { for breast cancer reduction } \\
(50)\end{array}$ & 12 & $\begin{array}{l}\text { Int } 93 \\
\text { Cont } 91\end{array}$ & $\begin{array}{l}18 \\
34\end{array}$ & $\begin{array}{l}-4.0(9 \mathrm{mo}) \\
-2.4\end{array}$ & $\begin{array}{l}-1.5 \\
-2.4\end{array}$ & +0.9 & No difference in \% body fat \\
\hline $\begin{array}{l}\text { Randomized trial of } \\
\text { moderate- vs low-fat diet in } \\
\text { weight loss (52) }\end{array}$ & 18 & $\begin{array}{l}\text { Low } 51 \\
\text { Mod } 50\end{array}$ & $\begin{array}{l}20 \\
35\end{array}$ & $\begin{array}{l}-5.1 \\
-4.9\end{array}$ & $\begin{array}{l}+2.9 \\
-4.1\end{array}$ & +7.0 & $\begin{array}{l}\text { Significantly more subjects on the low- } \\
\text { fat diet discontinued active participa- } \\
\text { tion }\end{array}$ \\
\hline
\end{tabular}

NCl: National Cancer Institute; Int: intervention; Cont: control; Mod: moderate.

In the study by Kasim et al. (47), fat intake was reduced to $17.6 \%$ of energy at 1 year, therefore providing a major contrast in diets. This study included more detailed data on body composition than most other investigations (Table 2) (47). The difference in weight change between intervention and control groups was somewhat greater than in the other studies, being $2.6 \mathrm{~kg}$. However, lean mass as well as fat mass was lost, so that the difference in change between treatment groups in percentage of body fat at 1 year was only $0.7 \%$ and no effect was observed on the waist-hip circumference ratio. Thus, despite a large contrast in diet, the change in adiposity was minimal and would not be perceptible or of clinical importance to an overweight individual. Importantly, the maximum difference in weight was seen at 3 months, with no subsequent divergence between groups.

A major limitation of most long-term studies of fat reduction is that the control group did not receive comparable dietary instruction and motivation. In these studies the intervention group was generally given state-of-the-art individual and group instruction and support to increase consciousness about dietary fat, sometimes including the provision of scales to weigh food and control portion sizes. 
Thus, changes in body weight, to the extent that they occurred, could have been the result of greater attention to overall food intake rather than just fat per se. To determine whether dietary fat reduction per se reduces body fatness, an appropriate control group would receive a similar intensity of dietary instruction and counseling but directed at the reduction of carbohydrate or total calories. Such a study was reported by Jeffery et al. (49). Participating women, who were initially moderately obese, received counseling either to reduce fat to $20 \mathrm{~g} \mathrm{~d}^{-1}$ or to reduce overall energy intake to $5000 \mathrm{~kJ} \mathrm{~d}^{-1}$. Both groups lost weight initially, but after 6 months they also regained weight in parallel (49); by 18 months there was no statistically significant or material difference between groups.

The importance of having a control group with an intervention of equal intensity was further demonstrated in a large randomized trial by Knopp et al. (52) among 444 men with hypercholesterolemia. These men were randomized to one of four levels of fat intake, and all groups lost between 2 and $3 \mathrm{~kg}$; the highest and lowest fat intake groups each lost $2.9 \mathrm{~kg}$.

McManus et al. (53) recently compared weight changes over 18 months between 101 overweight men and women randomized to either a standard low-fat diet ( $20 \%$ of energy) or a moderate-fat ( $35 \%$ of energy) Mediterranean diet. Although both groups initially lost weight, by 18 months only $20 \%$ of those in the low-fat group were actively participating in the diet program compared with $54 \%$ in the moderate-fat group $(p<0.002)$. At 18 months weight measurements were available for $31 /$ 50 subjects in the moderate fat group, who lost an

Table 2. Randomized trial of a low-fat (LF) diet in 72 women (47)

\begin{tabular}{|c|c|c|c|c|}
\hline & & Baseline & 12 months & Change \\
\hline \multirow[t]{2}{*}{ Dietary fat $(\% E)$} & LF & 36.3 & 17.6 & - \\
\hline & Control & 35.6 & 33.8 & - \\
\hline \multirow[t]{2}{*}{ Weight (kg) } & LF & 66.8 & 63.4 & -3.4 \\
\hline & Control & 72.7 & 71.9 & -0.8 \\
\hline \multirow[t]{2}{*}{$\%$ Body fat } & $\mathrm{LF}$ & 31.8 & 30.3 & -1.5 \\
\hline & Control & 35.1 & 34.3 & -0.8 \\
\hline \multirow[t]{2}{*}{ Waist-hip ratio } & $\mathrm{LF}$ & 0.74 & 0.73 & -0.01 \\
\hline & Control & 0.77 & 0.76 & -0.01 \\
\hline \multirow[t]{2}{*}{ HDL-C $\left(\mathrm{mmol} \mathrm{l}^{-1}\right)$} & LF & 1.56 & 1.44 & -0.12 \\
\hline & Control & 1.47 & 1.56 & +0.09 \\
\hline
\end{tabular}

The maximal weight change was seen at 3 months.

HDL-C: high-density lipoprotein cholesterol. average of $4.1 \mathrm{~kg}$, and $30 / 51$ in the low-fat group, who gained an average of $2.9 \mathrm{~kg}(p<0.001)$. During an additional year of follow up, the moderate-fat group sustained an average weight loss of $3.5 \mathrm{~kg}$. These findings are consistent with earlier work indicating that modest weight losses seen in the short term on low-fat diets are difficult to sustain in the long run. However, moderate fat intake in the form of a Mediterranean diet can be an effective strategy for sustained compliance and weight loss.

In any long-term study of dietary change, a major concern is that compliance may deteriorate with time, so that the lack of a substantial effect on body weight could simply be the result of a lack of difference in diets. Most studies of fat reduction have thus been hindered by a lack of a welldocumented measure of compliance. However, on low-fat diets blood levels of high-density lipoprotein cholesterol (HDL-C) are consistently depressed and triglyceride levels are increased (54). Thus, it is notable that the studies by Kasim and Lee-Han (47, 55) both demonstrated depressions of HDL on the low-fat diet that were maintained over time, documenting sustained adherence to diet. In the study by Knopp et al. (52), at 12 months the low-fat group experienced a $39 \%$ mean increase in fasting triglyceride levels, again documenting compliance with low fat intake. Thus, these studies do not support the notion that failure to observe a substantial weight loss on long-term low-fat diets is simply the result of non-compliance. A major objective of dietary change is to reduce risk factors for cardiovascular disease. Notably, the effect of fat reduction in these studies was to worsen blood lipid levels rather than improve them, because the predictable adverse effects of reduced fat intake were not counterbalanced by appreciable losses in weight.

\section{Short-term weight-loss trials}

One hypothesized reason to expect lower body fat on a diet with a lower percentage of calories from fat is the difference in metabolic efficiency of processing fat compared with carbohydrate or protein. Several studies of weight loss are relevant to this proposed mechanism $(56-58)$. In one of these studies, Powell et al. provided $5000 \mathrm{~kJ}$ diets to women randomized to $10,20,30$ and $40 \%$ of energy from fat. No significant differences were seen in weight change, although the magnitude of reduction was actually somewhat less on the lowest fat intake (56). Studies by Alford et al. (57) and Lehmann et 
al. (58) also found no effect of the fat composition of the diet on weight loss. These data consistently and clearly indicate that under realistic circumstances the theoretical differences in metabolic efficiency associated with different levels of fat intake do not account for appreciable differences in the rate of weight loss. These findings are consistent with evidence from metabolic studies that fat and carbohydrate sources of energy are stored with similar efficiency (20).

\section{Weight regain}

Astrup et al. (59) randomized 37 obese adults who had lost weight by a combination of energy restriction and drug treatment to either a low-fat, ad libitum diet or a complex system of calorie counting using 144 color-coded food markers. After 1 year, at which time the active program was terminated, there were no significant differences in the amount of weight regained. After an additional year, 28 subjects were reweighed. When the last recorded weight was used for the nine subjects not reweighed, there was a marginally significant greater weight regain in the calorie-counting group $(11.3 \mathrm{~kg})$ than in the low-fat, ad libitum group (5.4 kg). Differences in maintained weight loss from the initial weight loss were not significant before or after controlling for the initial method of weight loss. The authors concluded that the low-fat, ad libitum, high-carbohydrate diet was superior for maintaining weight after a major weight loss. However, this study is difficult to interpret because of the small size, the lack of data on fat intake in the two weight maintenance programs, and the use of carriedforward weights rather than only actual weights at the 1 year follow-up. To the extent that the differences may have been due to more than random variation or methodological bias, they may have resulted from a calorie-counting method that was too burdensome for sustained use, rather than from any differences in dietary composition.

\section{Discussion of intervention trials}

The long-term randomized trials of fat reduction provide strong evidence that the effect of dietary fat over a range of $18-40 \%$ of energy on body fatness is at most small and transient, and a long-term effect may not exist at all. The findings are particularly inconsistent with the hypothesis that body fat is proportional to dietary fat $(60,61)$ and the results of the meta-analysis of Popkins and Bray based on short-term studies. The lack of any important effect is particularly notable because, with the exception of the National Diet-Heart trial (45), and the studies by Jeffery (49), Knopp (52) and McManus (53), the design of the other trials was seriously biased in favor of finding an effect of fat reduction because the control groups did not receive an intervention with similar intensity. In the four studies with a control group that also received an intervention, the effect of fat reduction was -0.8 , $-1.4,0.0$ and $+7.0 \mathrm{~kg}$. Thus, the notion of "spontaneous" long-term weight loss when the percentage of energy is reduced is clearly not supported by randomized trials.

In addition to the meta-analysis by Bray and Popkins (10), which clearly has no relevance for long-term weight control, other meta-analyses of randomized trials of low-fat diets have been published by Astrup et al. $(14,59)$. The first of these meta-analysis (59) was severely flawed owing to the heavy influence of the study by Ornish et al. (62), which used an intervention that included regular physical activity, strict control of food availability, meditation and stress mitigation, in addition to fat reduction. A more recent meta-analysis by Astrup et al. (14) used more restricted inclusion criteria that resulted in 16 trials lasting for $2-12$ months. They reported that the low-fat groups lost on average 3.2 $\mathrm{kg}$ more weight than the control group, but that the amount of reduction in dietary fat was not significantly related to the amount of weight loss. Like the Bray and Popkins meta-analysis, this exercise is seriously misleading regarding the long-term effects of fat reduction, owing to the inclusion of studies lasting for only a few months. Even when long-term data for a study were available, the authors elected to use the shorter term results that showed a much larger difference in weight (38). In addition, one of the studies with the largest weight losses $(6 \mathrm{~kg})$ was a non-randomized low-fat intervention in which employees choosing to participate in the program were compared with those who refused the invitation, which would create a serious bias (63). The one study included in the meta-analyses, in addition to that by Kasim et al. (47) described earlier, which lasted for 12 months and appeared to show appreciable weight loss $(3.3 \mathrm{~kg}$ in men and $3.5 \mathrm{~kg}$ in women) with a reduction in the percentage of energy from fat $(7-8 \%$ of energy), was that by Stefanick et al. (64). However, it is unclear whether this was purely an effect of dietary fat, as controls 
received no counseling but those randomized to dietary change knew they were in a study that also involved physical activity and received individual and group counseling in which "weight loss was not emphasized". For all of these reasons, this metaanalysis cannot be considered a valid assessment of the long-term effect of dietary fat on body weight. Similarly, a meta-analysis by Yu-Poth et al. (65) is irrelevant to long-term weight control because they relied heavily on studies lasting for less than 1 year, and also included studies that combined fat reduction with physical activity and other interventions.

For the randomized trials lasting for 1 year or more (Table 1) the weighted mean difference between the low-fat and control groups is -0.25 $\mathrm{kg}$. In none of these studies did the effect of dietary fat reduction approach a $5 \%$ weight loss, which is generally considered to be clinically significant. The weighted mean difference for the effect of fat reduction among the studies in Table 1 that included a control group with comparable intensity of intervention $(45,49,52,53)$ was $+1.8 \mathrm{~kg}$, i.e. the control group tended to lose slightly more weight than the low-fat group. This is similar to the results of a recent meta-analysis by the Cochrane Collaborative (66) of long-term randomized trials of lowfat diets for weight loss, in which the control group was assigned overall caloric reduction. The weighted mean difference was $+3.7 \mathrm{~kg}(95 \%$ confidence interval -1.8 to 9.2 ) for studies lasting for 18 months or more, again consistent with greater weight loss with lower carbohydrate/higher fat diets.

In addition to the lack of an appropriate control group in many studies, other issues complicate what would seem to be a simple hypothesis to test. One of these is that fat reduction may be confounded by differences in fiber or in energy density of the diet. For example, in many of the fat reduction trials, subjects were generally counseled to consume high amounts of fruits and vegetables as well as whole grains and legumes. In one trial of fat reduction among elderly individuals (43), subjects continuing a baseline higher fat diet ( $35 \%$ energy from fat) were compared with an isocaloric low-fat diet. No weight loss was observed over a 12 week period, again documenting the lack of any important difference in efficiency of energy utilization. However, when subjects were allowed to eat the low-fat diet ad libitum for another 12 weeks, a modest weight reduction was observed. This diet was exceptionally high in fiber and had a low energy density, so that subjects complained of fullness and abdominal discomfort on the isocaloric low-fat diet. Thus, in this study, and potentially other studies, low-fat diets might be confounded by high fiber or low energy density. It might be argued that this is an inevitable and desirable consequence of a low-fat diet and thus should not be controlled in the design studies addressing the fat consumption of diets. However, low energy density is not an inevitable characteristic of low-fat diets as many of the low-fat foods presently being promoted in our commercial food supply are based on sugar or highly refined carbohydrates and often have a similar energy value to their high-fat counterpart. In contrast, in the Mediterranean tradition abundant amounts of vegetables are consumed along with whole grains and copious olive oil, thus providing a highunsaturated fat, high-fiber and high-volume diet. This may have contributed to the success of the moderate-fat Mediterranean diet in the study by McManus et al. (53). Because there is not an inevitable relation between the percentage of fat and energy density of diets, it is important to distinguish between these effects in the design of studies to assess the impact of the percentage of energy from fat on body weight. Whether the energy density of the diet has an important effect on longterm body fat is an important question itself. Shortterm studies suggest that energy density may affect body weight $(25,28,43,67-69)$. However, the contrasts between short- and long-term studies for dietary fat indicate the need for long-term studies of energy density and body weight before any conclusions can be drawn. In addition, it is possible that in highly sedentary populations with low energy demands, the energy density may need to be extremely low to have any important effect.

Besides energy density, other aspects of the diets being compared could potentially confound randomized trials of dietary fat composition on body weight. The form of the non-fat energy, which by definition increases as the percentage of energy increases, can potentially affect weight change. In addition to energy density, the protein content and glycemic characteristics of carbohydrate may be important in long-term weight control. Studies in animals consuming cafeteria-style diets suggest that palatability, flavor and texture may influence total energy intake (70). Subtle aspects of palatability may be difficult to control in any particular circumstance, but at least an attempt to do so 
should be made so as not to favor artificially one group or another.

\section{Other considerations}

The possibility exists that individuals vary in their genetic susceptibility, so that some will gain weight on high-fat diets where others will not. One study suggests that a family history of obesity might be an indicator of susceptibility to weight gain on high-fat diets (71), but these findings were based on extremely small numbers of subjects and implausible differences. Although susceptible individuals may exist, the lack of any substantial overall effect of fat reduction on body weight in the longer term randomized trials suggests that any susceptible subgroup is not large or that other people are susceptible to weight gain on high-carbohydrate diets.

Because dietary fat cannot explain the high prevalence of obesity and increases in excess body fat in many populations, alternative causes must be considered. Abundant evidence supports a central role of physical activity in the regulation of body fatness. Numerous cross-sectional studies indicate an inverse relation between physical activity and body fatness, and intervention studies demonstrate that increased physical activity at least stabilizes body weight and may lead to modest reductions (72). Roberts noted that the magnitude of physical activity in these intervention studies was small in relation to the levels of activity typical of nonindustrialized countries, so that the full potential impact of higher activity levels has not been adequately addressed in such investigations (72). The food industry has invested greatly in research on the texture, color, sweetness, saltiness and flavor of food, as well as on its packaging and promotion, all of which has been designed to enhance consumption. It seems highly likely that these efforts have contributed to overweight, although these contributions are difficult to quantify. Finally, the almost ubiquitous presence of food in our life and the convenience with which it is eaten is likely to contribute further to overconsumption, but quantification of these factors is difficult.

\section{Conclusions}

In short-term studies, a modest reduction in body weight is typically seen in individuals assigned to diets with a lower percentage of calories from fat. However, compensatory mechanisms appear to operate because in studies lasting for 1 year or more, fat consumption within the range of $18-40 \%$ of energy has little if any effect on body fatness. Thus, the use of short-term studies to predict longterm effects of fat reduction on body weight are completely misleading. Diets high in fat are not the primary cause of the high prevalence of excess body fat in our society, and the failure of population reductions in the percentage of energy from fat to reduce obesity in Western populations is consistent with the results of long-term randomized trials. Unfortunately, the emphasis on total fat reduction has been a serious distraction in efforts to control obesity and improve health in general.

\section{References}

1. Willett W. Dietary fat plays a major role in obesity: no. Obes Rev 2002; 3: 59-68.

2. Willett WC, Manson JE, Stampfer MJ, et al. Weight, weight change, and coronary heart disease in women: risk within the "normal" weight range. JAMA 1995; 273: $461-5$.

3. Grundy SM. How much does diet contribute to premature coronary heart disease? In: Stein O, Stein Y, eds. Atherosclerosis IX. Proceedings of the 9th International Symposium on Atherosclerosis. Tel Aviv: Creative Communications; 1992. p. 471-8.

4. Willett WC, Dietz WH, Colditz GA. Guidelines for healthy weight. N Engl J Med 1999; 341: 427-34.

5. Colditz GA, Willett WC, Rotnitzky A, Manson JE. Weight gain as a risk factor for clinical diabetes in women. Ann Intern Med 1995; 122: 481-6.

6. Felson DT. Weight and osteoarthritis. Am J Clin Nutr 1996; 63(Suppl): 430-2.

7. Seidell JC. Time trends in obesity: an epidemiological perspective. Horm Metab Res 1997; 29: 155-8.

8. Kato H, Tillotson J, Nichaman MZ, et al. Epidemiologic studies of coronary heart disease and stroke in Japanese men living in Japan, Hawaii and California. Am J Epidemiol 1973; 97: 372-85.

9. Flegal KM, Larkin FA. Partitioning macronutrient intake estimates from a food frequency questionnaire. Am J Epidemiol 1990; 131: 1046-58.

10. Bray GA, Popkins BM. Dietary fat intake does affect obesity! Am J Clin Nutr 1998; 68: 1157-73.

11. Kuczmarski RJ, Flegal KM, Campbell SM, Johnson CL. Increasing prevalence of overweight among US adults. The National Health and Nutrition Examination Surveys, 1960 to 1991. JAMA 1994; 272: 205-11.

12. National Research Council - Committee on Diet and Health. Diet and health: implications for reducing chronic disease risk. Washington, DC: National Academy Press; 1989.

13. World Cancer Research Fund, American Institute for Cancer Research. Food, nutrition and the prevention of 
cancer: a global perspective. Washington, DC: American Institute for Cancer Research; 1997.

14. Astrup A, Grunwald GK, Melanson EL, et al. The role of low-fat diets in body weight control: a meta-analysis of ad libitum dietary intervention studies. Int $\mathbf{J}$ Obes 2000; 24: 1545-52.

15. Astrup A. Macronutrient balances and obesity: the role of diet and physical activity. Public Health Nutr 1999; 2: $341-7$.

16. Pi-Sunyer FX. Effect of the composition of the diet on energy intake. Nutr Rev 1990; 48: 94-105.

17. Gershoff SN. Nutrition evaluation of dietary fat substitutes. Nutr Rev 1995; 53: 305-13.

18. Astrup A. Dietary composition, substrate balances and body fat in subjects with a predisposition to obesity. Int J Obes 1993; 17(Suppl 3): S32-6.

19. Flatt JP. Energetics of intermediary metabolism. In: Garrow JS, Halliday D, eds. Substrate and energy metabolism in man. London: John Libbey; 1985. p. $58-69$.

20. McDevitt RM, Poppitt SD, Murgatroyd PR, Prentice AM. Macronutrient disposal during controlled overfeeding with glucose, fructose, sucrose, or fat in lean and obese women. Am J Clin Nutr 2000; 72: 369-77.

21. Lissner L, Heitmann BL. Dietary fat and obesity: evidence from epidemiology. Eur J Clin Nutr 1995; 49: 79-90.

22. Chen J, Campbell TC, Junyao L, Peto R. Diet, life-style, and mortality in China: a study of the characteristics of 65 Chinese counties. Oxford: Oxford University Press; 1990.

23. Willett WC. Dietary fat and obesity: an unconvincing relation (Editorial). Am J Clin Nutr 1998; 68: 1149-50.

24. Centers for Disease Control and Prevention - National Center for 24. Health Statistics. Daily dietary fat and total food-energy intakes - Third National Health and Nutrition Examination Survey, Phase 1, 198891. MMWR Morb Mortal Wkly Rep 1994; 43(7): 116-7.

25. Lissner L, Levitsky DA, Strupp BJ, et al. Dietary fat and the regulation of energy intake in human subjects. Am J Clin Nutr 1987; 46: 886-92.

26. Dreon DM, Frey-Hewitt B, Ellsworth N, et al. Dietary fat:carbohydrate ratio and obesity in middle-aged men. Am J Clin Nutr 1988; 47: 995-1000.

27. Romieu I, Willett WC, Stampfer MJ, et al. Energy intake and other determinants of relative weight. Am J Clin Nutr 1988; 47: 406-12.

28. Tremblay A, Plourde G, Despres J-P, Bouchard C. Impact of dietary fat content and fat oxidation on energy intake in humans. Am J Clin Nutr 1989; 49: 799805.

29. George V, Tremblay A, Despres J-P, et al. Effect of dietary fat content on total and regional adiposity in men and women. Int J Obes 1990; 14: 1085-94.

30. Miller WC, Lindeman AK, Wallace J, Niederpruem M. Diet composition, energy intake, and exercise in relation to body fat in men and women. Am J Clin Nutr 1990; 52: $426-30$.
31. Colditz GA, Willett WC, Stampfer MJ, et al. Patterns of weight change and their relation to diet in a cohort of healthy women. Am J Clin Nutr 1990; 51: 1100-5.

32. Tucker LA, Kano MJ. Dietary fat and body fat: a multivariate study of 205 adult females. Am J Clin Nutr 1992; 56: 616-22.

33. Slattery ML, McDonald A, Bild DE, et al. Associations of body fat and its distribution with dietary intake, physical activity, alcohol, and smoking in blacks and whites. Am J Clin Nutr 1992; 55: 943-9.

34. Pudel V, Westenhoefer J. Dietary and behavioural principles in the treatment of obesity. International Monitor on Eating Patterns and Weight Control. Medicom/Servier 1992; 1: 2-7.

35. Klesges RC, Klesges LM, Haddock CK, Eck LH. A longitudinal analysis of the impact of dietary intake and physical activity on weight change in adults. Am J Clin Nutr 1992; 55: 818-22.

36. Lissner $\mathrm{L}$, Lindroos $\mathrm{AK}$. Is dietary underreporting macronutrient-specific? Eur J Clin Nutr 1994; 48: $453-$ 4.

37. Rissanen AM, Heliovaara M, Knekt P, et al. Determinants of weight gain and overweight in adults Finns. Eur J Clin Nutr 1991; 45: 419-30.

38. Sheppard L, Kristal AR, Kushi LH. Weight loss in women participating in a randomized trial of low-fat diets. Am J Clin Nutr 1991; 54: 821-8.

39. Puska P, Iacono JM, Nissinen A, et al. Controlled, randomised trial of the effect of dietary fat on blood pressure. Lancet 1983; i: 1-5.

40. Hunninghake DB, Stein EA, Dujovne CA, et al. The efficacy of intensive dietary therapy alone or combined with lovastatin in outpatients with hypercholesterolemia. N Engl J Med 1993; 328: 1231-9.

41. Levitsky DA, Strupp BJ. Imprecise control of food intake on low fat diets. In: Fernstrom JD, Miller GD, eds. Appetite and body weight regulation: sugar, fat and macronutrients. Boca Raton, FL: CRC Press; 1994: 179-90.

42. Shah M, McGovern P, French S, Baxter J. Comparison of a low-fat ad libitum complex-carbohydrate diet with a low-energy diet in moderately obese women. Am J Clin Nutr 1994; 59: 980-4.

43. Schaefer EJ, Lichtenstein AH, Lamon-Fava S, et al. Body weight and low-density lipoprotein cholesterol changes after consumption of a low-fat ad libitum diet. JAMA 1995; 274: 1450-5.

44. Westerterp KR, Verboeket-van de Venne WP, Westerterp-Plantenga MS, et al. Dietary fat and body fat: an intervention study. Int J Obes Relat Metab Disord 1996; 20: $1022-6$.

45. National Diet-Heart Study Research Group. The National Diet-Heart Study Final Report. Circulation 1968; 18(Suppl): 1-154.

46. Boyd NF, Cousins M, Beaton M, et al. Quantitative changes in dietary fat intake and serum cholesterol in women: results from a randomized controlled trial. Am J Clin Nutr 1990; 52: 470-6.

47. Kasim SE, Martino S, Kim PN, et al. Dietary and anthropometric determinants of plasma lipoproteins 
during a long-term low-fat diet in healthy women. Am J Clin Nutr 1995; 57: 146-53.

48. Black HS, Herd JA, Goldberg LH, et al. Effect of a lowfat diet on the incidence of actinic keratosis. N Engl J Med 1994; 330: 1272-5.

49. Jeffery RW, Hellerstedt WL, French SA, Baxter JE. A randomized trial of counseling for fat restriction versus calorie restriction in the treatment of obesity. Int $\mathrm{J}$ Obes 1995; 19: 132-7.

50. Simon M, Heilbrun L, Boomer A, et al. A randomized trial of a low-fat dietary intervention in women at high risk for breast cancer. Nutr Cancer 1997; 27: 136-42.

51. National Diet Heart Study Research Group. National Diet Heart Study Final Report. Circulation 1968; 37(Suppl 1): 1-428.

52. Knopp RH, Walden CE, Retzlaff BM, et al. Long-term cholesterol-lowering effects of 4 fat-restricted diets in hypercholesterolemic and combined hyperlipidemic men: the Dietary Alternatives Study. JAMA 1997; 278: 1509-15.

53. McManus K, Antinoro K, Sacks F. A randomized trial of moderate fat, low energy diet compared with a low fat, low energy diet for weight loss in overweight adults. Int J Obes 2001; 25: 1503-11.

54. Mensink RP, Katan MB. Effect of dietary fatty acids on serum lipids and lipoproteins: a meta-analysis of 27 trials. Arterioscler Thromb 1992; 12: 911-9.

55. Lee-Han H, Cousins M, Beaton M, et al. Compliance in a randomized clinical trial of dietary fat reduction in patients with breast dysplasia. Am J Clin Nutr 1988; 48: 575-86.

56. Powell JJ, Tucker L, Fisher AG, Wilcox K. The effects of different percentages of dietary fat intake, exercise, and calorie restriction on body composition and body weight in obese females. Am J Health Promot 1994; 8: 442-8.

57. Alford BB, Blankenship AC, Hagen RD. The effects of variations in carbohydrate, protein, and fat content of the diet upon weight loss, blood values, and nutrient intake of adult obese women. J Am Diet Assoc 1990; 90: 534-40.

58. Lehmann T, Golay A, James RW, Pometta D. Effects of two hypocaloric diets, fat restricted or rich in monounsaturated fat, on body weight loss and plasma lipoprotein distribution. Nutr Metab Cardiovasc Dis 1995; 5: 290-6.

59. Astrup A, Toubro S, Raben A, Skov AR. The role of low-fat diets and fat substitutes in body weight management: what have we learned from clinical studies? J Am Diet Assoc 1997; 97(Suppl): S82-7.

60. Flatt JP. The difference in the storage capacities for carbohydrate and for fat, and its implications in the regulation of body weight. Ann N Y Acad Sci 1987; 499: 104-23.

61. Flatt JP. Dietary fat, carbohydrate balance, and weight maintenance. Ann N Y Acad Sci 1993; 683: 122-40.

62. Ornish D, Brown SE, Scherwitz LW, et al. Can lifestyle changes reverse coronary heart disease? Lancet 1990; 336: $129-33$.

63. Baer JT. Improved plasma cholesterol levels in men after a nutrition education program at the worksite. J Am Diet Assoc 1993; 93: 658-63.

64. Stefanick ML, Mackey S, Sheehan M, et al. Effects of diet and exercise in men and postmenopausal women with low levels of HDL cholesterol and high levels of LDL cholesterol. N Engl J Med 1998; 339: 12-20.

65. Yu-Poth S, Zhao G, Etherton T, et al. Effects of the National Cholesterol Education Program's Step I and Step II dietary intervention programs on cardiovascular disease risk factors: a meta-analysis. Am J Clin Nutr 1999; 69: 632-46.

66. Pirozzo S, Summerbell C, Cameron C, Glasziou P. Advice on low-fat diets for obesity. Cochrane Library Review. Issue 4. Oxford: Update Software; 2002.

67. Kendall A, Levitsky DA, Strupp BJ, Lissner L. Weight loss on a low-fat diet: consequence of the imprecision of the control of food intake in humans. Am J Clin Nutr 1991; 53: 1124-9.

68. Shintani TT, Hughes CK, Beckman S, O’Connor HK. Obesity and cardiovascular risk intervention through the ad libitum feeding of a traditional Hawaiian diet. Am J Clin Nutr 1991; 6: 1647s-51s.

69. Poppitt SD. Energy density of diets and obesity. Int J Obes ; (Suppl) 1995; 19: S20-6.

70. Sclafani A. Dietary obesity. In: Stunkard AJ, Wadden TA, eds. Obesity: theory and therapy. New York: Raven Press; 1993. p. 125-36.

71. Heitmann BL, Lissner L, Sorensen TI, Bengtsson C. Dietary fat intake and weight gain in women genetically predisposed for obesity. Am J Clin Nutr 1995; 61: $1213-$ 7.

72. Roberts SB. Abnormalities of energy expenditure and the development of obesity. Obes Res 1995; 3(Suppl 2): 155-63.

\footnotetext{
Walter C. Willett, MD, DrPH

Department of Nutrition

Harvard School of Public Health

665 Huntington Avenue

Boston, MA 02I I5, USA

E-mail: Walter.Willett@channing.harvard.edu
} 